\title{
Aportes para un análisis de la crisis chilena*
}

La actual situación chilena no es fruto de las circunstancias, ni es extraña a la realidad nacional, a pesar de su sólida tradición democrática.

La estabilidad de la democracia, con los endénicos conflictos internos que le son típicos, exige no sólo fe en el sistema en que conviven ideas contradictorias o distintas que se respetan; sino que, para funcionar con eficacia y continuadamente, requiere gobiernos de mayorías estables, expresadas en especial por el consenso obligatorio entre el Ejecutivo y la mayoría de la opinión pública, cualesquiera sean las formas en que con autenticidad se la represente. En otras condiciones - aunque con minorías que mantengan la libertad- la forma democrática no tiene vigencia profunda o está sometida a tensiones tales que la llevan a una inestabilidad. o ineficacia peligrosas, como lo vemos hoy en muchos pueblos de nuestra misma tradición cultural, o a crisis de todo tipo en que la democracia termina sienclo traicionada. La historia contemporánea -en escala internacional y nacional- es una demostración continua de que los sectores $\sin$ fe en la democracia no están en condiciones de asumir su dirección, pues, originan un proceso confuso que conduce, por sus pasos contados, a la frustración, la crisis, la ruptura del sistema, la clictadura, a veces hasta la guerra.

El destino de los gobiernos de minoría es menos grave, si la minoría es democrática, e imprevisible cuando el poder pasa a manos de una minoría sin fe en la democracia. Fue el caso chileno.

La Unidad Popular llegó al gobierno dentro de la poderosa coruiente de libertades democráticas que Chile ha ido aumentando y ampliando a lo largo de su evolución política. Estructurada sobre la alianza que el Partido Comunista mantuvo, a cualquier precio y durante decenios con todo o con un sector del Partido Socialista, logró tras un arduo trabajo divisionista, atraer a fracciones de todos los partidos que habían perdido definitiva o transitoriamente su fe en la eficacia de los procesos democráticos para realizar el huma-

\footnotetext{
-Participaron en la discusión de este informe Benjamín Prado, Ricardo Valenzuela y Jaime Castillo.

Vale la expresión de Fourastié: Más de algo de lo dicho por nosotros, ya ha sido dicho por otros (Conditions de l'ésprit scientifique, París, 1972).
} 
nismo y acelerar el desarrollo. No obstante cuando la Unidad Popular asumió la dirección del Estado lo hizo sólo con el apoyo de poco más de un tercio de la opinión pública, y nunca salió de su condición minoritaria a pesar de las influencias que da el poder ${ }^{1}$. Por el contrario, la inescapable lógica de su esquema filosófico simple y dogmático, la fue transformando, con rapidez imprevisible en la clásica oligarquía marxista, cerrada, excluyente, y cada vez más reducida. Jugando el eclesial rol de estado dentro del estado, creyéndose depositaria de los intereses populares, perdió toda capacidad de análisis real. Alejada cacla vez más de la tradición política que le permitió ser gobierno $-\mathrm{y}$ con el voluntario olvido de las realidades de un país pequeño y cle sus condiciones geoeconómicasse orientó paulatinamente a imitar el casual, permitido, frenado y dependiente modelo cubano "revolucionario". Para ello fue configurando un proceso político que llevaría a la "suspensión de la democracia para dar después más denocracia”, en una especie de "historia relámpago" sintetizadora del esquema que Marx analizó para siglos.

Fue lo que Allende planteó en su primer Mensaje al Congreso Nacional.

En el manejo político concreto, si se exceptúa el afán estatizador, el gobierno de Allende no aportó ideas nuevas al proceso de modernización socioeconómica en marcha en Ghile desde hacía varias décadas. Ya en 1970 Chile era el tercer país latinoamericano en ingreso per cápita y en alfabetismo, a pesar de su ubicación geográfica, su escasa población, la repetida y continua destrucción de los terremotos, la caída del salitre y la cesantía consiguiente, que lo hicieron ser uno de los pueblos más afectados por la primera guerra y la crisis mundial de los años treinta. El cobre, constituido por enclaves extranjeros, sólo a partir de 1955 influyó decisiva y progresivamente en la economía nacional.

La planificación económica, la nacionalización de las riquezas básicas, la reforma agraria, la redistribución del ingreso, la masificación educacional, la participación popular, etc., eran todos procesos que estaban en marcha con apreciable éxito antes de 1971. El gobierno de la Unidad Popular sólo les trató de imprimir un ritmo tan acelerado como irrealista, además del carácter antiamericano violento que es otra característica "revolucionaria".

1Sobre el resultado de las elecciones parlamentarias de marzo de 1973, en que la Unidad Popular mejoró su posición relativa luego de cambiar la ley electoral, bay cargos de falsificaciones que deben aclararse En esa fecha la situación económica era tan caótica, que la Unidad Popular habría alcanzado un éxito, con sólo mantener su porcentrje de votos. Aun suponiendo una gran tarea concientizadora, los resultados obtenidos -precisamente en las zonas críticas para el gobierno- resultan inexplicables. 
Cualesquiera que hayan sido las intenciones, los resultados fueron el mayor desastre económico de la historia de Chile, el endeudamiento externo acelerado, un aumento en la dependencia internacional, la violencia en la vida diaria, la permanente crisis política agudizada por la condición de gobierno minoritario, la tentativa de usar las Fuerzas Armadas para objetivos partidistas y, por último, el fin de la democracia en Chile por un tiempo desconocido.

Condicionado por la acumulación de factores negativos en escala antes ignorada, todo to que la Unidad Popular trató de construir lo edificó en el aire, y cada uno de los que estimó sus "cambios irreversibles" está originando -casi por una ley física- un proceso de reversibilidad incontrolable, que puede poner en peligro el avance democrático de todo el siglo.

\section{II}

Es probable, no obstante, que los efectos de una visión tan distorsionada de la realidad chilena no hubieran llegado a límites extremos, si Allende, inexplicablemente dominado por una minoría alienada, no hubiera hecho un uso tan sectario y discriminatorio del inmenso poder que las leyes habían ido acumulando y centralizando en manos del presiclente de la República en los últimos cincuenta años. Es necesario, sin embargo, señalar que todos los sectores políticos son en alguna forma responsables de esta desviación estalinista de la democracia; traducida en las limitaciones de los cuerpos representativos, o en la falta de asesorías eficientes y amplias de los mismos para abordar los antiguos y nuevos problemas, cada vez más complejos, que debe ordenar la ley.

La Constitución del 25, junto con iniciar una nueva etapa presidencialista en Chile, surge con cuatro características que serán decisivas mientras el período crece, se clesarrolla y se agota.

-Ejecutivo muy poderoso, en que una misma persona es presidente de la República y jefe del gobierno;

- Participación creciente del Estado en la economía, manejada en gran parte por organismos autónomos dependientes del presidente de la República, situación que se robusteció y expandió extraordinariamente durante el gobierno de la Unidad Popular;

-Posibilidad de gobiernos minoritarios, responsables sólo ante el presidente de la República, sin que pudieran ser censurados por el Parlamento, o por la opinión pública a través de plebiscitos. Esta característica derivó en el uso -y hasta en el abuso- de la acusación constitucional contra algún ministro, como sustituto de la censura, 
$y$, durante el gobierno de Allende, en recursos para distorsionar la constitución así usada;

-Posibilidad de que el presidente de la: República no sea elegido junto con el Congreso, lo que generalmente impide mayorías y homogeneidad para gobernar, y no asegura la continuidad política por un tiempo prudente.

En resumen la Presidencia de la República era un centro de poder prácticamente omnímodo e inagotable y la estructura institucional permitía un dictador constitucional sobre cuya actuación, sólo se podía opinar cada seis años, votando a favor o en contra del candidato continuista.

Las distintas orientaciones que imprimieron a la nación los presidentes constitucionales del período, sin que ninguno de ellos dejara sucesor, excepto dos que murieron en el cargo con cuatro años de diferencia y en la etapa de más apoyo social al sistema, configuran uno de los principales factores del reducido y errático desarrollo económico de los últimos cuarenta años, a pesar de los notables esfuerzos de modernización que se realizaron durante la misma época. El lento crecimiento, coetáneo al masivo traspaso de poder generado por las grandes libertades democráticas -mantenidas durante tocla la vigencia de la constitución, incluso un tiempo en que la mayoría del parlamento declara fuera de la ley al Partido Comunista, hasta que otra mayoría lo reincorpora, -estimuló las ilusiones y los anhelos populares y de los sectores medios por una mayor inmediata y fácil participación; dio una filosofía para defenderse de los esfuerzos de apertura social a los sectores nacionales y extranjeros que dominaban la economía y, con las distintas metas de cada gobierno, desquició alternativamente el objetivo del desarrollo, hasta conducirnos al descontrol absoluto vivido durante los años 70 a 73 .

El error conceptual y político establecido en nuestra ley fundamental, que permite a los presidentes de la República imponer sus criterios sobre los de la mayoría nacional - a veces con el solo apoyo de un tercio de la representación popular-generó una técnica de interpretación jurídica, elaborada para las "legislaciones del veto", que debía formar una escuela que conduciría, lógicamente, al procedimiento de los "resquicios legales", destinado a usàr la complejidad de las leyes para interpretarlas tras objetivos prefijados y arbitrarios, recurriendo a disposiciones aisladas o en desuso. Este procedimiento generalizado y reiterado se transformó en el método para ir configurando un modelo de sociedad totalitaria, bajo aparente cobertura democrática. Culminó en conflicto cuando se le quiso usar para la modificación de la Constitución misma y así destruirla por dentro. 
En efecto, a partir de 1971 las características críticas del sistema van adquiriendo una agudización creciente.

La centralización del poder trata de ser total: el lema es asumir todo el poder.

La cada vez más extensa participación del estado en la economía se va transformanclo en una economía totalitaria, que se construye sin plan, ni medios, ni técnicos. Sin disciplina y con anarquía sectorial y generalizada.

El gobierno reduce, en vez de ampliar sus bases políticas. Falto de conducción, -en un sistema donde el presidente es el eje- los grupos minoritarios más violentistas pero más audaces, son los que dominan la combinación de gobierno, imponen su criterio y determinan las medidas que se adoptan tanto en el plano interno como externo. Hasta políticos extranjeros - como Castro- usan.de su poder ideológico y económico sobre estas minorías para influir determinantemente sobre lo que se clebe hacer en Chile.

El presidente de la República puede, y lo hace, marginarse de la opinión pública, ignorando lo que expresa el Parlamento cuya posición es ratificada en cada consulta popular, a pesar de la clescarada intervención y de la intimidación violenta de los ciudadanos.

En estas condiciones se generaliza en el país un clima de anarquía tan grave como no se había vivido nunca. Los esfuerzos de los grupos democráticos (Democracia Cristiana en especial) para producir una rectificación chocan con la incapacidad del presidente para apreciar la magnitud de la crisis que lo envuelve. Como ya dos veces ha sorteado las dificultades recurriendo a las Fuerzas Armadas, cree posible postergar indefinidamente una solución política democrática. Sus propios y principales colaboradores, en medio del clesorden social, la inflación desorbitada y hasta la falta de pan, increíblemente dogmatizados por experiencias extrañas -como la soviética y las tesis castristas- en vez de comprender y usar creativamente la clemocracia, complotan contra el sistema, organizando células de marineros, soldados, aviaclores y carabineros, confiaclos en que el poder presidencial y un imaginario "poder popular" que ellos manejarían, les darían impunidad y tiempo.

En este momento no es ya el sistema político, sino la existencia misma del país lo que está en juego.

Herida en su formación democrática, golpeacla por la anarquía, sacudida hasta el hambre por la situación económica, avergonzada 
de su nueva dependencia, fue la opinión pública y no la fuerza, la que hizo imposible que continuara el gobierno cle la Unidad Popular. Fidel Castro lo apreció cuanclo dijo que "la burguesía aprendía más rápido que el puelulo", interpretando a su manera la crisis chiJena. El golpe de las Fuerzas Armadas dejó indiferentes hasta a los sectores más populares politizados, si se exceptúa a los activistas, porque cuando ellas actuaron el juicio de la historia ya estaba dado.

La lucha política y social para mantener la democracia y para rectificar dentro del sistema, librada durante los últimos años, tal vez no tenga parangón en nuestra historia, a pesar de la violencia que se protegía y organizaba por la autoridad. La intervención de las Fuerzas Armadas fue inevitable sólo cuando la crisis tomó tales caracteres que pareció que existía el peligro de que la nación se desintegrara en un enfrentamiento preparado por los más variados sectores. El lema "no a la guerra civil" era la mejor fórmula psicológica del llamado a las armas.

\section{IV}

El "pronunciamiento" militar del Il de septiembre, no fue el resultado de una conspiración civil que ganó los cuarteles, aunque hubo muchos civiles chilenos y extranjeros que contactaron con los militares. Dada su precisión, rapidez y unidad, tampoco fue la acción de algún caudillo militar, pues sin duda alguna implicó un plan cletallaclamente preparado. Fue sí la convicción, adquirida especialmente en los últimos meses, de que los sectores políticos civiles no podían o no querían arriesgar una fórmula que, con su participación, diera salida al vacío de poder en que se debatía Allende.

Los militares son muy sensibles a la impresión de que el Estado se debilita, pues ellos se ubican siempre como servidores del Estado y no del Gobierno. Después de haber participado dos veces en resolver los complicados problemas de Allende en un nivel constitucional y legítimo, adquirieron una impresión definitiva de la debilidad del Estado, no sólo por la crisis política y económica permanente, sino porque sus propios representantes en el gobierno chocaron con una apreciación de la realidad que llevaba a la anarquía o con un temor de Allende de someter a la ley a algunos de sus aliados repitiendo la experiencia de González Videla con todas las consecuencias para su imagen personal y para las posiciones que habían sostenido sus colaboradores.

Los esfuerzos para defender la democracia habían resultado inútiles, pues la rigidez clel sistema político no daba salidas ante la inde- 
cisión del presiclente y la decisión de una minoría que se había instalado en el poder y que lo usaba contra la mayoría procurando alterar el sistema mismo. Desde ese momento el problema principal de Chile no era el de la clemocracia, ni siquiera el del socialismo o el del comunismo. El factor dominante había pasado a ser la anarquía que, creciendo bajo la tolernncia del gobierno, era un llamado inevitable a la fuerza.

En la acción cle los militares el país vio -simplemente- el término de la anarquía.

Esta fue la razón fundamental por la que un amplio sector del pueblo aceptó la situación producicla casi sin resistencia, y le dio inicialmente un apoyo importante.

La tradición jurídica del país entendíó la nueva autoridad como una especie de "Consulado" paxa salvar a la República, que se justificaba en la anárquica y dramática situación anterior y en la incapacidad marxista para absorber los procedimientos y exigencias de la vida democrática. Como todos los consulados de la historia, este se suponía por un tiempo limitado y también llevaba implícita una tregua política y la suspensión temporal de algunos derechos ciudadanos, sin que ello significara, en momento alguno, violación de derechos humanos o retrocesos de carḱcter social.

Las reiteradas declaraciones de las Fuerzas Armadas de que habían asumido el poder para procurar una pronta vuelta a la normalidad institucional -antes efectivamente subvertida- hizo que los partidos políticos democráticos y mayoritarios en Chile, aceptaran los hechos consumados como el resultado inevitable de la larga crisis agudizada por Allende.

La circunstancia de que altos jefes de las Fuerzas Armadas hubiesen actuado en el gobierno junto a los más avanzados líderes de la Unidad Popular, buscando alguna forma de estabilizarlo, cubría de intención legalista el rol político que asumían ante el pueblo, a pesar de que no es frecuente en Chile, que los generales reemplacen a los políticos.

La constante práctica de creciente violencia revolucionaria proclamada y practicada por el gobierno caído con formaciones de choque, como la Ramona Parra del Partido Comunista y la Elmo Catalan del Partido Socialista - avalada con la presencia de miles de extranjeros, verdaderas brigadas internacionales-, que durante los tres años de la Unidad Popular originaran centenares de enfrentamientos y muertes; el ensalzamiento continuo de la guerrilla y sus héroes por los elementos y partidos de gobierno (en Santiago existía un monumento al Che Guevara, erigido al margen de la disposición que exige que los monumentos sean aprobados por ley); además de la participación frecuente en los asuntos chilenos de los 
más implacables políticos extranjeros, criticada públicamente por el país, permitió por un momento explicar, aunque no justificar. la violencia inicial de los acontecimientos, a pesar de que contra la violencia había luchado la opinión democrática.

\section{V}

La Junta Militar que asume el poder en el conjunto de circunstancias descritas tiene algunas características sociológicas que ayudan a aclarar hechos y sus eventuales derivaciones.

En primer lugar, la Junta está compuesta por los Jefes de las instituciones armadas, todos con carrera profesional completa, realizada durante gobiermos de muy variada orientación. Algunos, inclusive, fueron designados por Allende. Es de suponer, por lo tanto, que son personas con una preparación profesional equivalente a la de sus similares en otros países y que tengan una visión de la realidad tan objetiva como lo exige o lo permite la carrera de las armas.

La importancia de los Altos Mandos de las Fuerzas Armadas no es valorizada suficientemente en las democracias, salvo en las etapas de crisis. En los estados totalitarios, por el contrario, su peso es decisivo, ya que cuando "los mariscales se suman a los inconformistas se producen los cambios de gobiemo". En los países latinoamericanos los ejércitos no son sólo el sector que más pesa en el presupuesto de los países, sino que, frecuentemente, el que usa y conoce los elementos más avanzados que la técnica, la informática y la ciencia ponen al alcance de las realidades económicas de cada pueblo en una época determinada. Los funcionarios superiores de los ejércitos tienen que conocer técnicas que se usan en las armas moclernas y que la industria nacional suele no producir. No obstante es un tipo de información y conocimiento que, por ser muy específicos originan -a pesar del contacto con la humanidad de la tropa- una frecuente desconexión con la realidad común del país.

Con tales antecedentes resulta decisiva para los juicios políticos de los militares, la orientación de las personas que les sirven de enlace con los problemas más generales del país, o el carácter de las informaciones, especialmente extranjeras, que reciben. No en vano los soviéticos invitaban a visitar su país y a tomar contacto con su oficialidad a los altos mandos militares chilenos, buscando compensar la tradicional influencia americana.

Los jefes de la Junta, como muchos de sus subordinados inmediatos, tienen una larga experiencia administrativa en el manejo de las instituciones militares. Se trata, sin embargo, de una administración 
estrictamente jerarquizada para realizar actividades que se programan con mucha anticipación y frecuentemente las mismas en diferentes oportunidades. Dentro de la administración del estado es el sector menos susceptible de conflictos, por lo que a veces se le posterga, aunque sus condiciones de vida en actividad sean, en las épocas normales, superiores a las de los demás funcionarios del Estado. La parte de los ejércitos dedicada a la producción -astilleros, maestranzas, fábricas de armas, etc.- se administra con criterios distintos a los de la actividad civil similar, por lo que tanto sus costos como su eficiencia son, en general, bastante diferentes. Este tipo de formación administrativa es más propia del socialismo que de la empresa competitiva privada, lo que hace pensar que sólo circunstancias transitorias pueden hacerles sentirse ligados a las fórmulas de la economía clásica y sus concepciones financieras. Es seguro que en este terreno se producirá un cambio, con el agregado de que los problemas que genera nuestro reducido mercado, requieren una administración más xígida y menos liberal, como ya se comienza a percibir:

La posición de la Junta frente a la "política" ha sido confusa y contradictoria. Al respaldo inicial que se buscó en la opinión política democrática, se está configurando posteriormente una actitud contraria a la "política", usando la expresión en su seṇtido más amplio. Para hablar contra los políticos, se habla contra la "demagogia", como si la dirección política no fuera una lucha constante entre la realidad y la demagogia, conservadora o revolucionaria. Tratanclo de presentar a los políticos como representantes de intereses, se olvida ingenuamente que siempre hay intereses ligados a los hechos de la vida, pero sólo de la confrontación de las plurales posiciones políticas e ideológicas que interpretan la realidad surgen resultantes que expresan el "bien común", el interés medio.

\section{VI}

Esta actitud casi universal de la milicia fiente a la política se explica en una triple experiencia que los condiciona en los países democráticos. En los países totalitarios la milicia es el sistema mismo o está ligado a él en forma fuertemente nacionalista.

En la etapa más importante de su vida, durante todo el servicio activo, en las democracias les está prohibido participar en política por razones reglamentarias. Fuera del contacto que se tenga a través de amistades personales, la política no debe ser parte de sus opiniones -especialmente públicas- lo que crea en muchos de ellos 
inhibiciones que sólo suelen romper con la espada. Sin embargo, su servicio profesional al Estado los obliga a respaldar la polftica contingente, que es variada y distinta según la orientación del gobierno elegido e incluso de los líderes, eventualmente militares, que ejerzan el mando en cada época. Inmersos con frecuencia en rumbos muy diferentes, terminan por apreciar más a las personas que a las ideas, posición que generalmente es también la de los poseedores de la riqueza, capaces de manejar hombres y visiones concretas, lo que en todas partes se traduce en una línea conservadora.

Sin embargo los hombres de arnas son también ciudadanos que viven los problemas de su tiempo, que forman parte de familias y de grupos sociales generalmente ligados a algún sector ideológico por las más variadas razones, intelectuales unas, materiales otras, más de alguna de origen moral y que viven los problemas comunes a toda sociedad.

La formación de los hombres de armas hace que se inclinen predominantemente a los sectores que expresen un patriotismo avanzado, una democracia de notables o cualquier forma que implique un cierto sentido de selección o de jerarquía. Los sectores "de orden" en la sociedad explotan estas inclinaciones con cierta eficacia transitoria, olviclando que los militares tienen sobre todos los políticos, los mismos prejuicios que los políticos tienen sobre los militares. Romper estos prejuicios es una tarea necesaria y de gran trascendencia en una época en que la militarización de la política es una realidad creciente, sobre todo en el Tercer Mundo.

Los miembros de la Junta, como en general los hombres de armas en Chile, provienen de los sectores medios, dependientes de sueldos, previsiones, estabilidad en el cargo, ascensos regulares, etc. No están ligados a las oligarquías financieras, a las gestiones internacionales, a la gran industria o a los grandes negocios. Están interesados, como la gran masa del país, en un desarrollo social y económico que les permita enfíentar sus problemas humanos en la mejor forma posible, sin diferencias abismantes que impiden la vida metódica a que acostumbra el orden militar. En estas características coinciden con los sectores medios del país, lo que hace que los intereses monopolistas traten de separarlos de ellos en forma sistemática, ya sea a través del halago social, ya sea usando la influencia de los medios de comunicación consolidados, que en las etapas de restricción democrática eliminan a los que viven de la opinión pública libre.

Como los valores de los sectores medios están indisolublemente ligados a la libertad que les permite la igualdad de oportunidades necesaria para progresar, los hombres de armas que han asumido roles políticos concretos, pronto se cansan del círculo de hierro a que los somete una restauración implacable políticamente y que 
generalmente mira al pasado. en su solución económica. Este proceso debe estar constantemente a la vista de nuestras Fuerzas Armadas para evitar que después de un "Cinco de Septiembre", se produzca un "Veintitrés de Enero", aun cuando cambios en la Junta serán inevitables como parte de la normalización del país.

-Al asumir el poder la Junta, los tres años de la Unidad Popular habían anarquizado completamente el proceso de modernización robusteciclo a partir de 1965 o antes. Era el resultado de la impotencia creaclora del marxismo vulgar y clel irrealismo intelectual de los hombres que lo encarnaban o acompañaban. A pesar de algunos avances que durarán, el desorden en todos los niveles en que se ahogaba el país cayó fuera del control del gobierno y salvo una participación de todos los partidos - con la formación de un gobierno nacional, con todos los partidos, como después de las guerras-, difícilmente podía ser rectificado por otra fuerza que no fuera "la ascendencia militar y su espíritu de disciplina".

Como pasa siempre en situaciones parecidas, se sobrevaloran los aspectos positivos que podrán aportar las Fuerzas Armadas, mantenidas hasta entonces en su posición profesional no sólo por formación, sino especialmente por la capacidad de resistencia y de lucha de las fuerzas políticas democráticas, que las habían sostenido en esta condición a pesar de los esfuerzos de Allende y la Unidad Popular por penetrarlas y comprometerlas con su línea. Las apreciaciones sobre la dirección impuesta al país por las Fuerzas Armadas, luego del "pronunciamiento" comienzan a cambiar, y el cambio se irá acelerando en un sentido crítico por la preeminencia que han vuelto a tomar valores políticos y económicos cuya sustitución se busca desde hace largo tiempo y frente a los cuales la Junta parece en una actitud de ensayo demasiado prolongada, como consecuencia, tal vez, del efecto "inseguridad" que asigna al "afán de novedades".

La "Formulación de Propósitos" en el mensaje de la Junta sobre la labor del gobierno, de fecha 10 de marzo de 1974 recién pasado, clestacan ya, en efecto, otros valores y criterios que los que se presentaron como objetivos del pronunciamiento militar.

Por encima del "resguarclo y defensa... de la identidad históricocultural" (Decreto Ley No 1 de 1973) de Chile se ve surgir un "ideario" -en general no muy nuevo y donde son también importantes los silencios- que en muchos aspectos parece contradictorio con lo que el país ha construido durante varias generaciones. El mensaje no es el de un Consulado, rectificador poderoso pero transitorio y preciso. En lata exposición, con planteamientos a corto y largo plazo, se propugna ahora, "crear las bases para el establecimiento de una real democracia... que permita alcanzar una nueva sociedad inspirada en el patriotismo, la solidaridad, la justicia y la 
participación responsables y eficientes de todos los chilenos en la construcción clel destino nacional... (Formulación de Propósitos) ${ }^{2}$ y que incluye una nueva Constitución (F. P.), modificación de códigos (‥ P. No 3, g. 3), nueva economía, etc. No es fácilmente compatible tal enunciado con el inicial "propósito de poner en marcha el restablecimiento de la institucionalidad con la mayor urgencia" (Decreto Ley 27). Se trata, en la nueva posición, de plantear cambios profundos -que pueden o no ser necesarios- pero que se deben pensar como destinados a durar, lo que sólo se consigue con el apoyo libre de la opinión pública participando en la formulación de los cambios. La alternativa es imponerlos a través de una dictadura rígida de duración indefinida, la misma intención de parte de la Unidad Popular y de todos los fascismos.

\section{VII}

Es sin duda cierto, como se puede afirmar conservadoramente, que las instituciones fundamentales en muchas naciones han surgido en circunstancias calificables de anormales, aunque se olvida con frecuencia el previo proceso ideológico. El caso chileno no ha sido muy distinto, pero las constituciones o sus reformas que más han durado se configuraron cuando las anormalidades parecían controladas o lo estaban efectivamente. Entre Lircay y el 23 de mayo de 1833 - fecha en que se promulga la constitución- transcurren casi dos años y un Congreso Constituyente convocado por autoriclades legítimas. La Constitución de 1925 se preparó por una Comisión convocada por el Presidente Constitucional de la República y se aprobó en un plebiscito. $\mathrm{Y}$ ambas fueron promulgadas por autoridades constitucionales, cualesquiera que hayan sido las circunstancias contingentes.

Si de las condiciones actuales se quiere que surja una nueva sociedad amparada por una nueva constitución, es necesario que se la prepare por organismos verdaderamente representativos, además de encontrar la forma para que oportunamente se la ratifique directa o indirectamente por el pueblo. La historia contemporánea nos muestra demasiados casos de cambios institucionales casi en serie o de cartas fundamentales que nunca fueron aplicadas, porque ellas no respondían al consenso e intereses profundos del pueblo, sino á ideologías irrealizables, presiones de grupos o momentos de poder Junta.

2F. P.: Son referencias a la declaración de Formulación de Propósitos de la 
asumido bajo signo distinto del que se consagraba en la norma. De nuestra actual crisis y de las experiencias más recientes puede resultar una institucionalidad humanista, moderna, abierta, con instituciones fuertes y.lógicas, capaces de afrontar de manera estable, justa y democrática la inevitable modernización integradora que tenemos por delante. Ello implica una continuidad de la histórica vocación de libertad de los chilenos, y de creciente participación del pueblo en todos los aspectos de la vida nacional. No puede ser el resultado de la opinión de los grupos transitoriamente dominantes.

Cuando se producen cambios de gobierno de la magnitud y en la forma acontecida en Chile en 1973 procurando terminar un "proceso de desintegración sistemática e integral" (Decreto Ley $\mathrm{N}^{\text {To }} 1$ ) de la nación, como el que se criticaba por muchos sectores, se presentan importantes coincidencias persiguiendo ese fin. Son sin embargo los individuos con menos preocupaciones ideológicas, con menos escrúpulos políticos y democráticos, con menos visión nacional y con más intereses afectados por la situación anterior, quienes rodean con rapidez a los nuevos gobernantes, en especial si estos no buscan o no desean la cooperación política que sólo le pueden prestar los sectores organizados, con ideas generales conocidas, y en condiciones de acercamiento razonablemente aceptables. Por lo común, en estos casos, se termina haciendo política con los que se autoproclaman "no políticos" y que suelen representar los más difíciles intereses, o se establecen contactos políticos secretos con personas experimentadas pero que desean rehuir responsabilidades frente a cir- cunstancias que no dominan, pero en las cuales no renuncian a influir.

La historia no es un conjunto de acontecimientos juxtapuestos, ni los intereses se generan o se disuelven en un momento; ambos procesos obedecen a corrientes profundas de la realidad nacional, que es necesario conocer detalladamente cuando se quiere formular cualquier política que no sea un acontecimiento pasajero. Esta tarea -entender lo que acontece- no es ciertamente papel de asesores ni de censores, sino es lo que pueden hacer quienes, durante años, han estado interpretando a sectores masivos de la opinión pública. La política es una disciplina a la vez intelectual y pragmática que requiere mucha capacidad, larga experiencia y apreciable espíritu de sacrificio, aunque más de alguno de sus intérpretes sea víctima de las linitaciones de la condición humana.

Para realizar una transformación tan compleja como la que se planter en el mensaje de la Junta, hay grupos humanos -cuya solidaridad se ha formado a lo largo del tiempo- que tienen mucho que decir y es necesario que lo digan. Si las circunstancias pueden explicar la marginación de sectores responsables de grandes trage- 
dias nacionales -el fascismo, el nacismo o el comunismo, según los países, como ha acontecido en circunstancias históricas-, nada debería impedir que quienes tienen una sólida formación democrática aporten, libre u organizadamente, su análisis para un eventual perfeccionamiento del sistema y de sus instituciones. Salvo que lo que se quiera hacer refleje sólo la visión de minorías sin destino, generando situaciones de poder pasajero, parecidas a la que Chile acaba de desestimar tan dramáticamente.

\section{VIII}

La traducción de este mensaje en una política para corto y mediano plazo se ha concretado en medidas de diverso alcance pero de honda significación.

En primer lugar es necesario repetir que el "pronunciamiento" se declaró por la democracia y contra la anarquía y que hoy la democracia no funciona. Aunque así era de esperarlo por un tiempo, no era igualmente previsible que el proceso político en vez de aproximarse a la democracia se degradara y se alejara de ella. La opinión pública se expresa hoy menos que diez días después del 11 de septiembre. Han desaparecido diarios democráticos. Se clausuran radios de la misma orientación. La situación de los partidos democráticos está hoy más afectada que antes de que se les declarara en receso. Los ciudadanos - no sólo los marxistas- viven bajo temor a la arbitrariedad. La justicia no da garantías a nadie.

Como en todos los países donde la democracia no funciona, los derechos humanos están afectados en una medida incontrolable. Con muy transitorios períodos de excepción, toda la vida republicana de Chile ha sido una constante lucha por la dignidad humana; cuyo continuo desarrollo se ha buscado en las leyes y en las instituciones, incluso anticipándose a pueblos de más alta evolución cultural y material que nosotros. Así se explican nuestros conflictos religiosos, los problemas educacionales, el sindicalismo activo, las nacionalizaciones aprobaclas por el Parlamento, hasta el fracaso de Allende al entregarse a la violencia, dañando a los hombres para alcanzar sus fines. Más que otros, Chile ha sido en América Latina y aun en toda América, el país de los derechos humanos, resguardados por una justicia que han ejercido exclusivamente tribunales establecidos por ley. Este alto prestigio y valiosa tradición, conocidos de una manera muy directa por tantos extranjeros que se refugiaran 0 se educaran entre nosotros, choca hoy con una indeterminada 
cantidad de duros hechos producidos después que el nuevo gobierno estaba ya consolidado.

"La violencia de los derechos humanos en cualquier parte del mundo puede ser conocida rápidamente por todos y ejerce una influencia nefasta, especialmente, en el exterior. Ningún gobierno puede ignorar que la protección de los derechos humanos y las libertades fundamentales se han transformado en una preocupación común de la colectividad internacional" (Consejo Mundial de las Iglesias, 1968, Estocolmo). Es un absurdo creer que cualquier violencia de los derechos humanos puede ser soslayada y evitar que golpee de una manera profunda contra los intereses nacionales, y aún si estas circunstancias son explotadas por "expertos en la lucha contra los derechos del hombre" que aprovechan su fácil audiencia y sus muchos medios para cubrir con los errores de otros sus propios errores. Si los casos en que están comprometidos militares en servicio activo deben ser vistos por la justicia militar, pasado ya más de medio año desde la instalación del nuevo gobierno todo indica la conveniencia de que sea la justicia ordinaria la que sustancie y resuelva los demás casos pendientes, aun cuando se mantengan las medidas de prevención o policiales permitidas en estado de sitio. Además de liberar a las Fuerzas Armadas de uno de los aspectos más críticos dentro de la pesada responsabilidad que han asumido, esta sola resolución desinflaría, más que cualquier otra, la campaña mundial que hoy existe contra el gobierno de Chile.

Como "toda persona tiene derechos a fundar sindicatos y a sincicarse para la defensa de sus intereses (Declaración Derechos Humanos, 23), resulta especialmente delicada la situación de los sindicatos en la nueva configuración sociopolítica que se está delineando. Después de haber luchado tan vigorosamente contra la distorsión sectaria del monopolio sindical que manejaron los marxistas - pero que todos los sectores contribuyeron a crear-, surge ahora un nuevo y más fuerte monopolio de hecho, con cuyo silencio se pretenden reforzar un proyecto económico en el cual el trabajo se siente disminuido y para cuya formulación no ha sido consultado. Este cuadro resulta tanto más conflictivo cuanto que en otros países tradicionalmente conservadores de América, se busca a través de fórmulas libremente convenidas, como el "pacto social", un camino para afrontar realidades económicas también difíciles, en una perspectiva de estabilidad y de efectivo crecimiento del mercado, pero consagrando una decisiva participación al trabajo.

En la situación actual de los sindicatos se hace inútil la eliminación de los dirigentes extremistas. Desde la clandestinidad explotarán las angustias y las limitaciones económicas que efectivamente existen, sin que los excluidos o limitados dirigentes sindicales de- 
ESTUDIOS INTERNACIONALES

mocráticos estén en condiciones de enfrentarlos con eficacia en la imposibilidad de defender una política socioeconómica configurada sin su participación, como ya antes se lo enrostraron a la Unidad Popular.

El problema de los derechos humanos rebota igualmente en la compleja situación que afecta al pensamiento, a la intelectualidad y en especial a la vida universitaria y científica. El universal esfuerzo marxista por usar la cultura y la cátedra para sus fines de propaganda, en Chile llegó al extremo cuando la violencia de la Unidad Popular -manejada en especial por los miristas- pretendió implantar el terror en las Universidades e impedir la expresión plural y democrática de las mayorías docentes y estudiantiles. La vigorosa actuación de los sectores democráticos que ya en 1973 habían recuperado el control de casi todas las Universidades, tuvo siempre una orientación positiva y abierta, en lucha constante por la libertad del espíritu.

En circunstancias mucho menos difíciles que las sufridas por Chile, en otras partes se ha suspendido la autonomía de las Universidades, se ha decretado su intervención y aun se las ha puesto bajo el control de la fuerza pública, de tal modo que nadie se puede llamar a escándalo por nuestra actual crisis universitaria. No obstante es indudable que en este sector, como en el sindical, sólo una vigorización y defensa de los valores democráticos puede satisfacer la angustia existencial del estudioso y del dirigente, y combatir con éxito significativo y duradero las distorsiones de la inteligencia totalitaria. La Universidad entiende $\mathrm{y}$ siente los derechos humanos como valores incorporados a su patrimonio espiritual. En aquellos pueblos donde el sistema los niega metódicamente, nada detiene la inquietud universitaria -y la inteligencia - como prólogo, generalmente, de situaciones más conflictivas.

El olvido de los derechos humanos es el factor más áctivo para que las diferencias políticas, que siempre existen, degeneren en violencia. Su falta constante origina la violencia sin término. No hay razón alguna para creer que Chile puede ser una excepción a lo que nos muestra la realidad contemporánea. Todo hace pensar que cuando no funciona la democracia, así como hay una violencia pública, hay también una violencia súmergida que tiene organización, líderes, medios, "samizdats". Los propios hombres de gobierno se encargan de recordarlo frecuentemente, entre otras razones para explicar las medidas de fuerza.

Sólo la restauración de los derechos humanos, en especial abriendo la vía de la justicia para la convivencia ciudadana, impedirá que contradictorios pactos de sangre terminen dominando la vida pública chilena. Cuando un gobierno transitorio quiere cambiarlo todo, 
es posible que, también, cambie el tadicional enfrentamiento ideológico de la democracia por uno violento, haciendo madurar la línea que quisieron imponer los extremistas partidarios de Allende. No sólo por razón de principios, sino por motivos también muy. concretos, es una exigencia imperiosa que el respeto a los derechos humanos vuelva a ser el factor dominante en la vida chilena.

EI hombre necesita ser informado sobre lo que acontece a su alrededor, de manera veraz y amplia. Cuando falta una información objetiva, independiente y aun crítica, todos los rumores y todos los rigores toman consistencia, originando una reacción sentimental que, en definitiva, debilita a los gobiernos, porque el sentimiento es duro enemigo. Conocer siempre la verdad ha sido la mejor arma para defenderla, y su ocultamiento se presta para los graves juicios que suele reservar la historia. Aunque es razonable que en determinados momentos se retenga información considerada importante para la seguridad colectiva, nada aconseja restricciones inútiles, conocidas las actuales posibilidades técnicas que hoy existen para informarse sobre los hechos. El problema se agrava cuando, como acontece en Chile, manejan el control de las retenciones informativas y aun de las informaciones quienes son contraproducentes para el momento recuperador, aunque hayan servido en las horas críticas y para la tarea crítica. Como la tarea actual es descontinuarse del anárquico proceso anterior y retomar la identidad histórico-cultural de Chile, que se caracteriza por una constante apertura democrética, es necesario que manejen la información, mientras sea exigido, personas cuya fe en la democracia no provoquen inquietudes ni dudas. En este campo tan delicado de los derechos humianos no se puede seguir comprometiendo a las Fuerzas Armadas por la acción de "orientadores o censores" incontrolados que terminarán llevándolas a serios problemas cuando surjan, dentro de ellas mismas, quienes asuman la dura responsabilidad de rectificar.

\section{IX}

En Chile la ley común e impersonal dio carácter a la vida del país. En manos de aristocracias, oligarquías o clases medias, la ley fue abriendo paso a una sociedad democrática dominada por la razón. Durante un siglo y medio - desde Napoleón hasta Nixon- las Fuerzas Armadas chilenas, luego de consolidada la Independencia, y aprobada la Constitución . de 1833 sólo actuaron en pronunciamientos o golpes de Estado, entre 1924 y 1931 -en el cambio social y 
la crisis mundial de los años treinta-, y ahora en 1973, en la tentativa populista de Allende que, al posponer la ley a la aventura, acabó con el populismo, y también con la democracia, en medio de una crisis de magnitud y alcance no conocida antes en Chile.

El gobierno militar asumió el poder en medio de una situación económica en extremo caótica, porque la Unidad Popular buscó siempre o casi exclusivamente objetivos políticos con las medidas económicas. La suerte y duración del nuevo gobierno, sin heredar dicho criterio, estará, sin embargo, ligada en gran medida al éxito o fracaso de su política económica, desde el momento mismo en que se la identifique como política de la Junta y no como las duras consecuencias de los errores de Allende.

La Unidad Popular procuró substituir la modema tendencia planificadora, participacionista y controladora de la democracia económica, en pleno desarrollo antes de 1970, por el Capitalismo de Estado que practican los marxistas. Tras ese objetivo se usó de la presión directa, de los resquicios legales y, sobre todo, de la amplia libertad con que el Presidente de la República podía manejar muy extensos sectores de la èconomía, directamente o a través de las entidades y empresas autónomas. Como en cada área o empresa se siguió el proceso ortodoxo del capitalismo de estado totalitario, el interventor y el partido reemplazaron la visión de los trabajadores y técnicos, sobreponiendo los objetivos de poder a la eficiencia del modernó manejo económico con las inevitables consecuencias productivas.

La nacionalización de las riquezas básicas y de los servicios públicos aún en manos extranjeras - buscada por el país y realizada ya en gran parte antes de 1970- se caracterizó por un irrealismo internacional $y$ un sectarismo interno suicidas. Las decisiones exclusivamente políticas, como la distribución del manejo de las minas, empresas y servicios por cuotas entre los partidos de gobierno y la "fijación de indemnizaciones por utilidades excesivas" pasando por encima de todo procediniento elementalmente razonable, fueron medidas que se impusieron a los intereses patrióticos, en la clásica línea del pensamiento marxista que al luchar contra un imperialismo, terminan trasladando la dependencia a otro entre los más poderosos y actuales.

El colectivismo estatal en la agricultura generó los mismos resultados productivos que en otras partes $y$, realizados en forma "rápida, drástica y masiva" a lo largo del país, nos hizo depender en todos los rubros y en una escala antes desconocida del aprovechamiento externo, situación que a pesar de los esfuerzos que se hagan durará años, además de haber dado origen al endeudamiento más rápido de nuestra historia. 
La anarquía política, económica y financiera, eliminarón durante tres años toda inversión importante y no dieron posibilidad a proyectos, programas o planes nuevos o de ampliaciones. $\mathrm{Y}$ lo que es más grave originaron la expatriación de algunos miles de profesionales ligados al desarrollo económico. Ambos problemas no se resolverán sin estabilidad política.

Para enfrentar todos los aspectos de esta grave crisis, la Junta se ha ido acercando cada vez más a un tipo de política económica clásicamente capitalista, encubierta bajo el confuso nombre de "economía de mercado". El mercado perfecto, que implica el proyecto, no existe en parte alguna del mundo actual ya que desde los precios y los salarios hasta los aprovisionamientos están condicionadios en las pequeñas o grandes naciones; y Chile se halla muy lejos de la masa poblacional crítica que el modelo exigiría para un mercado aproximadamente libre. Ni aun las Compañías Transnacionales pueden contar con ese mercado perfecto, a pesar de su habilidad y poder para evitar las "restricciones regionales" de los países o áreas.

La realidad chilena de hoy en economía es un proceso de restauración inspirado en los criterios e intereses más tradicionales, retrocediendo a fórmulas que el país fue superando a lo largo de varios decenios. Todo el proyecto parece reducirse a un régimen de trabajo disciplinado, salarios fijos y precios libres, disminución de planificación y eliminación de controles, contrariando todas las políticas exitosas con que se han afrontado las grandes crisis en los últimos cincuenta años ${ }^{3}$. Los resultados comienzan a producirse, con un mercado que se achica en medio de una inflación sostenida y una cesantía creciente, sinjultánea con una sostenida acumulación de divisas - generada en la coyuntura internacional- sin que estos hechos pesen en la pólítica físcal y monetaria, pensadas fuera de la nueva realidad posterior a las nacionalizaciones. ${ }^{*}$

3Por ofrecer una política parecida - desmovilizar toda la estructuna económica de la guerra en un instante- los ingleses sacaron a Churchill del poder, cuando aún era el héroe triunfante de la contienda mundial.

El desastre chileno era tan gigantesco que hacía pensar en soluciones como Ia NIRA de Roosevelt y en las medidas de Adenauer con su "mitbestimmungsecht" de 1951 y 1956.

*EI precio del cobre y la renegociación exitosa de la deuda externa, permitiría una reforma monetaria (a la - alemana) con mercado abastecido (eventualmente desde el exterior) mientras se pone en marcha un plan de desarrollo que retome el ritmo del crecimiento anterior al 72 y no retroceda en. la redistribución del ingreso. 
Precisamente sólo el sector nacionalizado en que se han restablecido, junto con la disciplina, la planificación y los controles, como el cobre, la recuperación es apreciable y significativa en producción física. Parece, en cambio, poco menos que imposible que se restaure con rapidez y eficacia una economía en que se pasa del control total (unos tres mil productos en la Unidad Popular) a ningún control (menos de veinte hoy día), basándose en que es posible someter a los monopolios u oligopolios privados, en circunstancia que se comprueban tan fuertes como el gobierno mismo, lo que se vio en el gobierno de Allende. En los mercados pequeños -y tal vez en los grandes- sólo se les controla algo con una política económica dirigida y apoyacla por la opinión pública.

Cuando se sienten protegidos por el poder en forma selectiva, los sectores económicos fuertes chocan, adicionalmente, con los sectores medios - además de los bajos- representados, en especial, por el sector público (en Chile, 1974, con cerca de un $70 \%$ del Producto Geográfico Bruto y otro tanto de la inversión), lo que explica los frecuentes ataques contra la "burocracia y los políticos" que los conocen y, en alguna medida, Ios controlan.

Si bien hay un error incalificable en despreciar la capacidad creativa y administrativa de cualquier hombre de empresa, es también una ingenuidad esperar que no actúen conforme a la naturaleza de su formación e intereses. Las sociedades modernas construyen ecuaciones adecuadas entre la imaginación y la comunidad, estimulando solidaridades que aceleran el desarrollo pero que sólo dentro de la democracia adquieren un carácter humano de servicio eficiente y comunitario como lo demuestra el mundo actual. Pero esta solidaridad sólo es verdadera en una sociedad abierta o en las etapas de imperio triunfantes. Entre nosotros sin un apoyo político importante será imposible configurar una política económica eficaz y con la cual se sienta comprometido un vasto moviniento de opinión.

Las Fuerzas Armadas no podrán seguir ligadas a una economía pensada para una sociedad distinta de la chilena en sus dimensiones y desarrollo (respecto de la cual los propios. tecnócratas dudan) sin que surjan en su seno conflictos de gravedad creciente.

Cuando los centros de la economía mundial -Europa y Estados Unidos, sacudidos por la crisis energética que exigirá grandes inversiones internas- se inclinan y buscan fórmulas más eficientes a la vez que más democráticas, es extraordinariamente difícil que se produzcan'inversiones extranjeras significativas en Chile si, además de haber nacionalizado las recién hechas, falta la presentación política que le ha dado prestigio e imagen a este país. Las posibilidades para invertir relativamente similares que ofrece el área andina - de la cual, en otro de sus errores, Allende nos desligó tres 
años- trabajan en contra de los países en que la dictadura ha reemplazado a la democracia, sin que las condiciones financieras o tributarias que se pueden ofrecer tengan diferencias decisivas, como se podía hacer antes del Acuerdo de Cartagena. En estas circunstancias sólo la minería puede tener interés real para alguna inversión, pero es precisamente en este sector en el que la opinión pública está más sensibilizada, y en el cual un cambio de la política nacionalista seguida por varios gobiernos requerirá la extraordinaria sutileza política, salvo que las Fuerzas Armadas quieran asumir un papel difícil de explicar al país.

Si descontamos los aumentos en el precio y producción del cobre, sólo la política agraria puede trabajar con significativa libertad y rapidez en el mejoramiento de las condiciones económicas generales, ya que es posible esperar de la agricultura nacional ingresos que impliquen mejorar en varios cientos de millones de dólares nuestra balanza de pagos. Es sin embargo curioso comprobar la desorientación que existe en el sector agrario porque, como no hay libertad ni tranquilidad para la discusión pública de la política seguida, tanto el problema de la propiedad de la tierra, como el de los precios de los productos, de los insumos, repuestos o salarios $-\mathrm{y}$ en especial el de los créditos- están originando, pero ahora para una mayor masa empresarial si incluimos a los asentados, el mismo ambiente de incertidumbre tradicional en la actividad agrícola chilena, aumentada por el incontrolable efecto de la inflación sobre los sienpre estrechos resultados agrícolas. Por otra parte todo el proceso social y económico ha hecho de la agricultura el sector más terriblemente descapitalizado del país, lo que es contradictorio con la política crediticia seguida últimamente.

Es de la mayor urgencia que un sector afectado por tan grandes transformaciones en los años pasados y donde parece existir una gran clase media en formación - que to hace proyectarse como uno de los más decisivos de la nueva sociedad que surgirá de la ya prolongada crisis chilena-, reciba una orientación ideológica que responda a la fisonomía histórico-cultural del país defendiendo y robusteciendo las ideas democráticas, cualesquiera que sean las circunstancias contingentes. Si esto no sucede, el campo será la base para enfrentamientos de imprevisibles formas, como vemos en tantos países de nuestra América, donde el doloroso parto de la nueva y modema sociedad, se refugia especialmente en el sector campesino. 


\section{XI}

Dentro de este análisis es necesario ubicar, desde nuestro punto de vista, a las demás fuerzas políticas y sociales que existen entre nosotros y que activa o pasivamente influyen hoy en el curso de los acontecimientos.

El primer factor de poder actual son las Fuerzas Armadas, algumos de cuyos rasgos se analizaron anteriormente. A pesar de su extraordinaria presencia pública, resulta difícil aceptar que tengan conciencia clara de la crisis en que actúan; sepan que no son ellas quienes dominan la crisis; y que hay una crisis profunda, no de poder, en pleno desarrollo.

$\mathrm{Si}$ bien la situación actual es fruto de una etapa de anarquía que las instituciones hicieron posible, todo este proceso hay que insertarlo en el esfuerzo de modernización que una sociedad democrática como la chilena, vive más intensamente que otras sociedades cerradas.

Se moderniza cuando el país se integra, incorporando un tercio de su población - los campesinos- a la libertad, a -la igualdad, a la propiedad, a la cultura. Cuando el país se hace dueño de sus servicios públicos o de sus fuentes fundamentales de ingresos. Cuando se distribuye razonablemente este ingreso. Cuando se acaba con el analfabetismo y se amplía la cultura superior. Cuando la inmensa mayoría de su población participa regularmente en la elección del poder político y efectivamente en el poder socioeconómico. La etapa en que se van alcanzando estas metas es, en general, una crisis prolongada, en el sentido de época de transición, que ya usaban los griegos.

La participación de las Fuerzas Armadas en este proceso debe ser importante. Tal vez el error chileno fue no incorporarlas cuando la crisis tenía los caracteres democráticos de su desarrollo históricocultural, porque las Fuerzas Armadas, no pueden estar en contra de la urgente modernización.

En las circunstancias de hoy, sin embargo, la crisis ha tomado otra dirección. Ahora no se quiere modernizar, sino restaurar y bajo el pretexto de restaurar, a las Fuerzas Armadas se les está haciendo servir intereses que, por su formación y sus necesidades patrióticas, no pueden compartir. Es una etapa en que después que el proceso de modernización democrática fue distorsionado y el gobierno pasó a las Fuerzas Armadas, los hombres viejos quieren reconstruir la socjedad a su imagen y semejanza. Es el más difícil instante de la crisis, aquel que se vive entre el pasado y el futuro 
porque el presente no está perfilado. Es cuando los antecedentes que provocaron la anarquía pueden reactualizarse y contribuir a detener la modernización inevitable y prolongar la crisis.

Las sutiles influencias internacionales cobran en dichos momentos, una importancia que las Fuerzas Armadas conocen mejor que nadie, que saben que son difíciles de resistir pero que, por formación, siempre desean mantener alejadas. Aunque las apariencias puedan ser otras, la historia señala que las Fuerzas Armadas optan siempre por mirar hacia adelante y habrá una oportunidad o unos hombres que les permita deshacerse de quienes buscan restaurar fórmulas envejecidas.

Como la modernización es inevitable, la crisis estará en desarrollo tanto tiempo como sea necesario para que surjan expresiones de poder sostenidas por la.razón y los valores morales, que sirvan más aliá de las fuerzas para incorporar a la sociedad chilena al mundo que viene. En esta etapa las Fuerzas Armadas también serán afectadas por las contradicciones vivas de una sociedad en cambio, pero terminarán dando preeminencia a los elementos modernizadores sobre los conservadores. Ese instante hay que acelerarlo porque entonces empieza una nueva normalidad.

\section{XII}

Imposibilitado para actuar por la destrucción de sus principales trentes -Partido Comunista, Partido Socialista, Central Unica de Trabajadores-, y el desaparecimiento, la prisión o la huida de sus líderes, el marxismo enfrenta uno de los momentos más duros que ha vivido en Chile. Como suponen que -salvo circunstancias internacionales- su ostracismo político será largo, aun en el caso de una nueva normalidad, a los marxistas no les debe interesar la solución de Ia actual crisis, sino el agudizamiento de sus "contradicciones". Incluso es probable que estén divididos, con el sector violentista preparando enfrentamientos y el evolucionista en una autocrítica sobre sus incapacidades para la democracia. Saben también, que los intereses norteamericanos que en la década del 50 detuvieron a Stalin en Europa y en la del 60 a Mao en Corea y Vietnam, no permitirán que en América se pase más allá de la experiencia cubana.

En todo caso es un hecho que dentro del país se les ve más silenciosos que poco después de la caída de la Unidad Popular. Hasta la actividad subterránea que se les adjudica, parece suspendida, si se juzga por las apariencias. Se presume, sin embargo, que deben tener jefes en una clandestinidad bien protegida; y se sabe que cada día reciben desde el exterior noticias bastante completas, co- 
mentarios e instrucciones. Es imposible conocer cuántos miles de personas atienden o las escuchan y menos aún cuántos grupos funcionan. Pero si había células hasta en las Fuerzas Armadas, a pesar de la vigilancia del Servicio de Inteligencia Militar, bien se puede suponer que más de alguna del país se está reorganizando. Basta recordar que en 1969 un 31 \% del electorado votó por parlamentarios marxistas.

Aunque se tenga ahora una visión extremadamente crítica del período de Allende, no hay duda alguna de que varias medidas de su gobierno irán adquiriendo importancia de "divortium acquarum" histórico, o se las presentará así por un sector significativo de la opinión. No es imposible que se vaya configurando un nuevo Balmaceda, con retratos que irán pasando desde los escondidos baúles a los salones.

La nacionalización del cobre, racionalmente conducida antes de Allende, pronto será una obra de Allende: la hizo luchando contra Estados Unidos, y se hablará del "bloqueo invisible" visualizándolo en un precio del cobre que se dobla al poco tiempo de caer Allende y antes de la crisis petrolera. La reforma agraria, se tratará de presentarla como obra de Allende: las demás serán ensayos de laboratorio o de macetero. Las tentativas socializantes, aunque anárquicas, serán un esfuerzo precursor en un mundo que se socializará cada día más. Al pueblo se le dirá que tuvo poder y participación legalmente adquiridos y que se los robaron los restauradores. Como el marxismo tiene una eficacia crítica extraordinaria, organizada y repetida, reconstruirá su visión simplificada de la historia, con el agregado romántico y trágico de miles de muertos en la lucha de los pobres contra los ricos, de las colonias contra el imperialismo, de la libertad contra la dictadura. El propio marxismo se encargará de poner a Allende en su santoral, pero lo importante será el marxismo.

En la medida que el actual régimen fomente el "receso de las ideas políticas", elimine la posibilidad de debate democrático, se sostenga en un gremialismo inocuo, que ya empieza a dividirse, -como le angustia al propio El Mercurio-, porque le falta el sustento y la contradicción ideológica que le daba la vida; en la medicla que la reconstrucción económica se continúe haciendo sin el debate público libre que sólo pueden conducir los movimientos políticos y el capitalismo clásico rehaga su poder y repita sus errores; en la medida que las disposiciones salariales, tributarias y financieras empobrezcan a las clases medias, mayoría del país sostenedora de la democracia, todo le irá dando argumentos al marxismo para volver a la carga en cuanto se lo permitan las circunstancias, con el agravante de que podrá acusar a los movimientos democráticos de no haberse jugado por el pueblo en los momentos críticos. Ningún 
cuerpo sin alma se salva de la petrificación y en las naciones ni las tareas de desarrollo o de chauvinismo reemplazan el debate ideológico como la expresión viva de una sociedad.

El maxxismo como gobierno es siempre una dictadura implacable, pero en la oposición lucha contra la dictadura y forma Frentes Amplios, Frentes Populares, Uniones Populares e incluso Asociaciones de Perseguidos por la Dictadura, para unir fuerza cuando le conviene y en lo que le conviene, eligiendo el momento psicológicosocial oportuno, que siempre se presenta por razones coyunturales.

Suprimir la actividad y libertad política cle los movimientos democráticos, en especial de los populares, es trabajar para que el marxismo mantenga su vigor aun en medio de la persecución.

Si en los sindicatos, en las universidades y en los medios de comunicación, la modernización no tiene sólidos refuerzos ideológicos y humanos de inspiración democrática, y se mantiene sólo una posición negativa o una construida sobre valores anticuados como las que hoy día se plantean, el maxxismo mantendrá en sus tres principales campos de acción la potencialidad larvada que resultan de las contradicciones de una sociedad sin salidas humanistas. Sólo las ideas políticas y no la fuerza lo han limitado y dividido en la realidad contemporánea interna de occidente. Si el proceso de modernización se interrumpe en Chile o se frena más allá de lo crítico, si el imperialismo recupera posiciones perdidas, hasta es posible que en las propias Fuerzas Armaclas surja un lícler maxxista que, con más experiencia que un Prestes, concite opinión y apoyo en forma imprevisible.

Entretanto, el maxxismo se centrará en la campaña internacional para hacer de su derrota en Chile un triunfo; de sus errores, la culpa de sus enemigos políticos; del desastre económico, el resultado de la presión yanqui, y de su mala conducción política, la consecuencia del divisionismo chino $y$, para algunos marxistas, de la acción de Castro. Como los partidos políticos democráticos están en receso, deberán mantenerse callados, y los "diplomáticos o políticos a presión", seguirán haciendo declaraciones tan afortunadas como las que se acaban de expresar en Venezuela.

El trabajo fundamental del marxismo, en esta hora, es prejarar, en Chile y en el extranjero, nuevos hombres que, con pocos de los ya conocidos, actuarán en la actividad sindical y en la política, en las condiciones que se planteen en un futuro que esperan proféticamente, pero que pasa primero por un período de exclusión legal "nueva ley de Defensa de la Democracia, o cláusula constitucional que les prohíbe actuar". En todos los países que tuvieron un régimen de fuerza o fascista este proceso se ha dado paulatina o velozmente, en función de las circunstancias nacionales (por ejemplo los co- 
munistas ligados a Rusia son los enemigos de la nación alemana, que incluso dividieron $y$ por eso tienen hoy poco poder). En los países con apertura política e ideológica, el marxismo comunista-soviético es una importante fuerza detenida en su crecimiento.

La política de la Junta frente a la política ayuda al marxismo.

La Derecha, actúa en dos frentes: el político y el económico. En el primero cobra diviclendos por su participación en la lucha contra la Unidad Popular, que, en general, dio con decisión aunque sin visión del futuro.

Como representa una larga experiencia, sabe que la vuelta a formas democráticas en Chile será inevitable, pero estima conveniente prorrogax todo lo posible el interregno militar. Espera que en este plazo se realicen una serie de cambios a actuales leyes "demagógicas", que resultaría casi imposible alcanzarlos en condiciones normales; que se elimine a personas duclosas de influencias importantes - como universitarias, financieras, internacionales$y$, sobre todo, que se destruya a fondo los focos de marxismo, incluso dentro de las iglesias. Pero, en lo posible, que todo se haga sin participación oficial de los políticos de derecha porque, al menos sus sectores más tradicionales, tienen conciencia que la democracia, que sirve a todos los hombres, también los protege cuando su expresión política funciona normalmente.

Espera, en especial, que en la medida que el interregno sea más largo se debilite la democracia cristiana, a la que se sindica de cómplice comprometido y culpable ideológico del proceso allendista porque la "anarquía había empezado antes". Pero más que debilitada, espera verla dividida, pues es posible que algunos de sus hombres sean necesarios si las circunstancias se complican.

La Derecha económica hará todo lo posible para que la actual realidad política se transforme en un largo "proceso a la brasilera". Los intereses privados que incluso esperan heredar parte del sistema previsional - por la vía de los seguros-y aspiran a la desnacionalización de cualquier o toda actividad financiera o productiva creen que esto sólo es posible en un régimen sudamericano típico.

Un orden de disciplina laboral, salarios fijos y precios libres, moneda fluctuante y orden público se aproxima al esquema ideal que ha buscado durante años. Sus medios de publicidad se están jugando a consolidarlo y a buscar el apoyo internacional requerido para tal fin. Incluso en sus organismos más representativos, está colocando a elementos duros y con contactos internacionales visibles.

En efecto es imposible pensar que los intereses norteamericanos, cuya actuación en las presidencias anteriores se debe calificar de 
hábil y. sutil, no estén vivamente interesados en los aspectos políticos y económicos envueltos en la actual etapa chilena. Tal vez su prudencia esté ligada a la debilidad de Nixon, a la mala imagen de las compañías transnacionales y a la fuerte presión de los "liberales" norteamericanos ya embalados en la campaña presidencial. Sin embargo no hay duda que está en marcha una "operación limpieza", que pasa por el desaparecimiento de Perón y cambios sustanciales en Perú, luego de eliminado Allende. Unos ochenta mil millones de dólares de inversiones extranjeras difícilmente pueden aceptar la teoría de las "utilidades excesivas" -que empezamos a oír en la Venezuela de Pérez- ni en política una ampliación de la influencia soviético-cubana. Cualquier proyecto sociopolítico exige un análisis agotador de este problema y el diseño de fórmulas nuevas para afrontarlo, pues de otro modo será -el imperio y su poder- la herramienta tradicional en manos de la derecha económica o de la izquierda clásica, para sus respectivos fines. Sin embargo, como el pueblo norteamericano aprecia los valores democráticos sobre todo otro valor -incluso los negociossu política chilena, en definitiva, se acercará a los sectores que busquen restaurar la democracia, con la sola condición que ello no abra camino para otra experiencia prosoviética.

Entretanto es de esperar que las influencias norteamericanas serán crecientes en el actual gobierno y en gran medida se realizarán vía institucional-profesional militar, tanto por la presente situación chilena como por lo que se ha llamado la "militarización" de la política de unos Estados Unidos, considerados "desde Pearl Harbour como nación en guerra", y enfrentados ahora a situaciones complejas en extremo. El sentido pragmático norteamericano, tratará de afianzar estos contactos y el poder que los origina, dada su dilatada experiencia en toda Latinoamérica, ya que saben bien que para éste o para otro gobierno, el actual cuadro económico no se empieza a resolver sin aporte apreciable de capitales y técnica extranjeros.

Tal vez habría que decir algo sobre el rol de las iglesias, en especial la Iglesia Católica, en la defensa de los derechos humanos y del trabajo, que las hace aparecer en una posición siempre contradictoria con vastos sectores tradicionales y muchos de sus voceros, En esta línea, sin jugar papel político alguno, es indudable que contribuye de manera directa al restablecimiento de la democracia y las normas del humanismo implícitas en el sistema. Puede que ésté sea uno de los motivos porque la atacan tanto quienes desean prolongar el interregno. 


\section{XIII}

El rol de la Democracia Cristiana, es bastante más complejo que el de todos los sectores antes analizados. Como su inspiración vital es la democracia, toda quiebra o limitación de la democracia, la afecta en su esencia misma. Hoy es la existencia de la Democracia Cristiana, la que está cuestionada, a pesar cle su vigorosa representatividad de los sectores medios, del sinclicalismo'independiente y de vastos núcleos intelectuales.

Enfrenta un serio problema de claridad ante el pueblo.

Luchó para evitar que la anarquía acabara con la democracia, y no pudo impedir que la caída de Allende arrastrara a la democracia. Su defensa de los derechos humanos, la ha llevado al problema de los clerechos ciuclaclanos. Su representación pública hoy no puede expresarse y nadie sabe cuándo podrá hacerlo. Sus clirectivas no funcionan y sus líderes están clivididos y dispersos. El ciudaclano común no conoce su pensamiento.

El movimiento demócrata cristiano mundial está en una posición crítica sobre el rol jugado por la Democracia Cristiana en Chile. Hay incertidumbre sobre su capacidad de recuperación y se teme que viva una crisis interna más profunda que las que ya tuvo que soportar.

Para la gente de la dictadura, la Democracia Cristiana es una esfinge que sonríe. La mayor parte de los técnicos, mandos medios y hasta dirigentes sindicales que, junto con los militares, manejan el estado son demócratas cristianos. Para los generales no importa la posición de los dirigentes si cuentan con la cooperación de los dirigidos, e incluso se ufanan de contactos políticos con dirigentes demócratas cristianos, en grupos distintos, y seleccionados por ellos. Estiman que los antiguos dirigentes que "contribuyeron a la caída de Ibáñez" están estigmatizados de antimilitarismo y confían -apoyados en esto por la derecha- en que ya no tendrán oportunidad cle actuar y que serán reemplazados por otras promociones.

En todo caso es una enseñanza de la historia, y también de la nuestra, que todas estas grandes agudizaciones de las crisis dan origen a renovaciones ideológicas $y$, frecuentemente, a nuevas fórmulas políticas.

Con el Pronunciamiento del 11 de septiembre, termina un período de medio siglo que tal vez pueda ser llamado en el futuro "el ascenso y pulverización de la clase media democrática". 
Ignacio Palma Vicuña / Aportes para un análisis de la crisis chilena

La etapa se fue transformando en una crisis permanente cuando ningún sector político fue capaz de darle, a ese vasto sector social una dirección unitaria y la conciencia de su destino histórico común. Es uná tarea pendiente.

Santiago, abril de 1974. 